of pulmonary embolism in Cases 2 and 3 was obtained by pulmonary angiography, using an intravenous route which in acutely ill patients is better tolerated than introduction of a catheter into the right ventricle (Williams et al., 1963). The elevated serum lactic dehydrogenase supported the diagnosis of pulmonary embolus in Case 2 but was unhelpful in Case 3. Wacker and Snodgrass (1960) have drawn attention to a raised serum lactic dehydrogenase in the presence of normal serum glutamic oxaloacetic transaminase as being of diagnostic value in pulmonary embolism. The respiratory studies with regard to the low pulmonary diffusing capacity are in keeping with the findings of Sasahara et al. (1964) in four patients with pulmonary embolic disease.

Characteristic of many published reports of thrombotic disease on oral contraceptives has been a relatively serious clinical picture. Eleven fatal cases were noted at the time of the 1962 Chicago Conference. Subsequently two of the six cases described by Schatz et al. (1965) had major pulmonary emboli and a third case required amputation of a limb for arterial thrombosis. A fatal case of superior mesenteric artery thrombosis was recorded by Reed and Coon (1963). In the case reported by Cohen and Sajid (1964) death was due to massive pulmonary thromboembolism. Hartveit (1965) has described the case of a 32-year-old woman who died with coronary thrombosis while on Anovlar.

\section{Summary}

Three healthy women developed intravascular thrombosis while receiving oral contraceptive therapy. Case 1 was fatal and directs attention to the possibility that arterial thrombosis may also exist in addition to the more common thrombophlebitis of the legs and pulmonary embolism.

We would like to express our gratitude to many people who have helped us with these cases: to Professor G. M. Bull for his permission to publish Case 1 ; to Dr. P. Balmer and Dr. J. Willis for the necropsy report and post-mortem studies; and to Dr. E. $\mathbf{M}$. McIlrath for the pulmonary angiogram investigations.

REFERENCES

Baines, G. F. (1965). Brit. med. 7., 1, 189.

Brakman, P., and Astrup, T. (1964). Lancet, 2, 10.

Brit. med. F., 1962, 2, 315.

Chicago Conference (1962). Conference on Thrombo-embolic Phenomena in Women. Searle.

Cohen, M. G., and Saiid, M. H. (1964). Delaware med. 7., 36, 81.

Egeberg, O., and Owren, P. A. (1963). Brit. med. F., 1, 220.

Food and Drugs Administration (1963). Final report on enavid by the ad hoc committee for the evaluation of a possible etiologic relaad hoc committee for the evaluation

Gaylis, H., and Kramer, M. V. (1962). S. Afr. med. F., 36, 1080.

Gaylis, H., and Kramer, M. V. (1962). S. Afr. med. 7., 36, 1080. Surg. Gynec. Obstet., 110, 327.

Hartveit, F. (1965). Brit. med. F., 1, 60.

Humphrey, J. G., and Newton, T., H. (1960). Brain, 83, 565.

Hutchinson, E. C., and Yates, P. O. (1960). Postgrad. med. F., 36, 14.

Johnson, H. C., and Walker, A. E. (1951). F. Neurosurg., 8, 631 .

Jordan, W. M.'(1961). Lancet, 2, 1146.

7. Amer. med. Ass., 1963, 185, 131 .

Leather, H. M. (1965). Lancet, 1, 270.

Lemmen, L. J., Davis, J. S., and Radnor, L. L. (1958). F. Neurosurg., $15,438$.

Lorentz, I. T. (1962). Brit. med. f., 2, 1191.

McIntyre, N., Phillips, M. J., and Voigt, J. C. (1962). Ibid., 2, 1029. MCWilliam, R. S., MacDonald, A. J., and Lindsay, I. (1963). 'Canad. med. Ass. 7., 88, 1032.

Mills, W. G. (1964). Proc. roy. Soc. Med., 57, 207.

Minogue, W. F., Halperin, I. C., Soler-Bechara, J., Varriale, P., and Flood, F. B.' (1963). New Engl. F. Med., 268, 1037.

Morrell, M. T., Truelove, S. C., and Barr, A. (1963). Brit. med. 7., 2, 830.

Phillips, L. L., Turksoy, R. N., and Southam, A. L. (1961). Amer. J. Obstet. Gynec., 82, 1216.

Reed, D. L., and Coon, W. W. (1963). New Engl. F. Med., 269, 622.

Richman, G. (1962). Brit. med. f., 2, 729

Sasahara, A. A., Stein, M., Simon, M., and Littmann, D. (1964). New Engl. $尹$. Med., 270, 1075 .

Schatz, I. J., Smith, R. F., Breneman, G. M., and Bower, G. C. (1964). 7. Amer. med. Ass., 188, 493.

Sobrero, A. J., Fenichel, R. L., and Singher, H. O. (1963). Ibid., 185, 136.

Staddon, I. S. (1962). Brit. med. f., 2, 857.

Stevens, A. E. (1961). Lancet, 2, 1005.

Stewart-Wallace, A. M. (1964). Brit. med. F., 2, 1528.

Wacker, W. E. C., and Snodgrass, P. J. (1960). F. Amer. med. Ass., 174, 2142 .

Williams, J. R., Wilcox, W. C., Andrews, G. J., and Burns, R. R. (1963). Ibid., 184, 473.

Zilkha, K. J. (1964). Brit. med. F., 2, 1132.

\title{
Aftercare of Artificially Paced Patients
}

\author{
RODNEY BLUESTONE,* M.B., M.R.C.P., D.oBST.R.C.o.G. ; ALAN HARRIS,* B.SC., M.B., M.R.C.P. ; \\ GEOFFREY DAVIES*
}

Brit. med. F., 1965, 1, 1589-1592

During the past four years 96 patients have been treated at this hospital with permanent pacemakers (Harris et al., 1965). They have needed careful supervision to ensure continuation of satisfactory pacing, and to study and deal with complications.

The technical problems entailed (Davies and Sowton, 1964) have resulted in the setting up of a special weekly follow-up clinic, to which most of these patients return at regular intervals. For many patients artificial pacing has been lifesaving and has enabled them to return to a normal existence, but it can be maintained only by specialized aftercare techniques (Davies and Sowton, 1964 ; Sowton and Davies, 1964), our personal experience of which we describe below in some detail.

\section{Pacemaker Systems in Use}

Epicardial Electrodes, Attached to an Implanted Abdominal Pacemaker.-Most patients with this system have two electrodes

* From St. George's Hospital, London. attached to their heart, one of which is spare and the other connected by a stainless-steel wire to a pacemaker unit implanted in the rectus sheath. Their platinum indifferent electrode is implanted in the subcutaneous tissue near the unit.

Epicardial Electrodes, Attached to an External Pacemaker.The electrode wires emerge from the abdominal subcutaneous tissue to connect with a small unit worn externally.

Endocardial fugular Catheter, Attached to an Implanted Pacemaker (Siddons and Davies, 1963).- These patients are paced by means of a solid electrode catheter passed via an external, occasionally internal, jugular vein and wedged at the apex of the right ventricle. The proximal end of the catheter has been fixed in the neck, then drawn down behind the clavicle to the axilla, where it is connected to an implanted unit. The indifferent electrode lies in the subcutaneous tissues of the axilla, adjacent to the unit.

Endocardial fugular Catheter, Attached to an External Unit. -The electrode catheter is positioned as above, but emerges from the neck vein to connect with a small unit. The indifferent 
electrode is buried in subcutaneous tissue, usually in the neck, near to the catheter exit for convenience.

\section{Normal Pacing}

Most of the units are set to deliver an impulse regularly at a fixed rate between 60 and 80 a minute, and should not vary. As alterations of only five beats a minute may be significant, the pulse should be counted over a full minute, and a long E.C.G. strip will show whether the pacemaker stimulus is followed on all occasions by a QRS complex (see Fig. 1). The

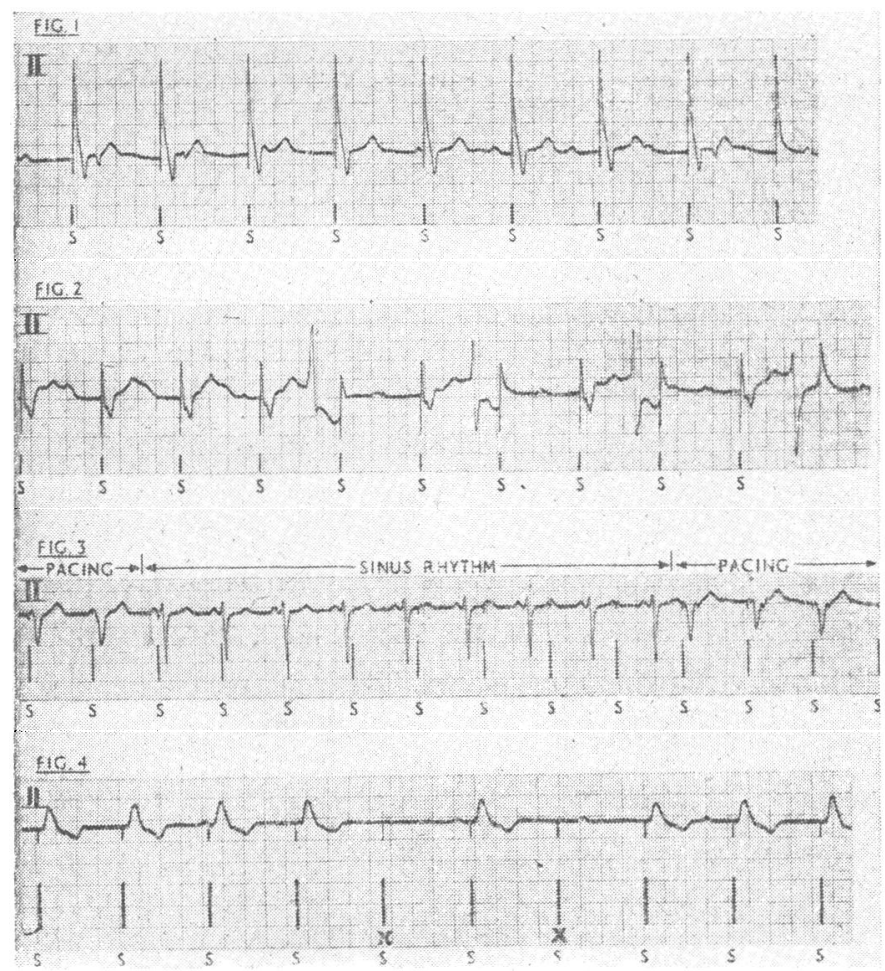

FIG. 1.-Uncomplicated pacing at a rate of $67 /$ minute. E.C.G. shows pacemaker stimuli, marked $S$, each of which is followed by a QRS and T complex which is associated with effective ventricular contraction. FIG. 2.-Satisfactory pacing. E.C.G. shows ventricular ectopics, giving an irregular rhythm, but each pacemaker stimulus is followed by a ventricular contraction except when it falls during a refractory phase. FIG. 3-Satisfactory pacing. E.C.G. shows a spell of sinus rhythm during which the pacemaker stimuli fall during the refractory phase and are thus without effect. At the beginning and end of the strip uncomplicated pacing is evident. FIG. 4. - Intermittent pacing. E.C.G. shows that the two stimuli marked $\mathrm{X}$ fail to provoke a ventricular response. rate of discharge may also be counted electrically on a measuring oscilloscope, thus checking the radial pulse rates and excluding any error due to the recorder running at the wrong speed.

The arterial pulse may be irregular, however, in the presence of competition from a return to sinus rhythm or the intrusion of ventricular ectopic beats. An E.C.G. will then show paced complexes, sinus or ectopic complexes, and periods in which pacemaker stimuli fall during a refractory phase, producing no response (see Figs. 2 and 3). The patient is often aware of the arrhythmia, but some complain of palpitations and tachycardia which may even result in syncope. This may be a transient phenomenon and explain a patient's symptoms even if an E.C.G. shows uncomplicated pacing at the time of interview. Admission for E.C.G. monitoring and a trial of cardiodepressor drugs (quinidine, procainamide: adrenergic B-blockers) is sometimes needed.

Some patients remain in congestive heart failure despite satisfactory pacing at an optimal rate, as shown by output studies (Sowton, 1963 ; Segel et al., 1964). These patients respond to digitalis and diuretics, and may need to be maintained on these drugs as well as being paced.

\section{Manifestations of Faulty Pacing}

Intermittent pacing will cause an irregular pulse, and the E.C.G. will show pacemaker stimuli failing to provoke a response, even in non-refractory periods of the cardiac cycle (see Fig. 4).

A slow regular pulse may be due to complete cessation of pacing, with a return to idioventricular rhythm, or to an abnormally slow unit discharge, as a manifestation of battery exhaustion. A slow ventricular rate is particularly apt to precipitate runs of ventricular tachycardia or fibrillation. Some units were designed to speed up as the batteries ran out, causing tachycardia ; but this is now recognized as being an even less desirable feature.

\section{Causes of Faults}

Any system of artificial pacing is dependent on a batterydriven electronic device, and although electronic failure is now uncommon battery exhaustion is ultimately inevitable. The introduction of foreign material into the body may result in sepsis or rejection of that material. Endocardial electrodes may become dislodged or internal wires fracture, and external wires and connexions are susceptible to repeated stresses and strains (see Table).

Table to Show Complications, Faults, and Treatment

\begin{tabular}{|c|c|c|c|c|}
\hline \multirow{2}{*}{$\begin{array}{l}\text { Possible Faults Causing Interference } \\
\text { with Pacing; and Other Complica- } \\
\text { tions }\end{array}$} & \multicolumn{4}{|c|}{ Treatment } \\
\hline & $\begin{array}{l}\text { Epicardial Electrodes : } \\
\text { Buried Abdominal Unit }\end{array}$ & $\begin{array}{l}\text { Epicardial Electrodes : } \\
\text { External Unit }\end{array}$ & $\mid \begin{array}{c}\text { Jugular Endocardial Electrode } / \\
\text { Buried Axillary Unit }\end{array}$ & \begin{tabular}{|} 
Jugular Endocardial Electrode: \\
External Unit
\end{tabular} \\
\hline $\begin{array}{l}\text { Electrode cracked or detached from } \\
\text { endocardium or epicardium }\end{array}$ & \multicolumn{2}{|c|}{$\begin{array}{l}\text { Admit for operation and utilization of spare electrode, or re- } \\
\text { placement to different system }\end{array}$} & \multicolumn{2}{|c|}{$\begin{array}{l}\text { Reposition or replace catheter under } x \text {-ray screen, as out-patient } \\
\text { procedure with local anaesthetic if possible } \\
\text { When reattachment to buried } \\
\text { unit required, do under } \\
\text { general anaesthetic }\end{array}$} \\
\hline $\begin{array}{l}\text { Faulty indifferent electrode } \\
\text { Fracture external wire : faulty junction }\end{array}$ & \multicolumn{2}{|c|}{ Implant new electrode ; under local anaesthetic if external unit; } & \multicolumn{2}{|c|}{ admit and general anaesthetic if buried unit } \\
\hline $\begin{array}{l}\text { Fracture external wire : faulty junction } \\
\text { Unit failure (electronic or battery ex- } \\
\text { haustion) }\end{array}$ & $\begin{array}{l}\text { Admit for exploration and re- } \\
\text { placement }\end{array}$ & $\begin{array}{l}\text { Repair } \\
\text { Replace }\end{array}$ & Exploration and replacement & Replace \\
\hline Abdominal/thoracotomy sinuses & $\begin{array}{l}\text { Conservative measures so long } \\
\text { rise, intermittent or failed pac } \\
\text { May need to exteriorize wires } \\
\text { to enable an external unit of } \\
\text { greater power to pace }\end{array}$ & $\begin{array}{l}\text { as possible. Expect threshold } \\
\text { cing } \\
\text { May need to abandon for dif- } \\
\text { ferent system if threshold on } \\
\text { epicardial wires rises to } \\
\text { above } 6.0 \text { volts }(150 \mu \text { joules). } \\
\text { May need to remove obso- } \\
\text { lete epicardial electrodes and } \\
\text { wires at later date if sinuses } \\
\text { severe and persistent }\end{array}$ & & \\
\hline $\begin{array}{l}\text { Axillary wound breakdown (actual or } \\
\text { threatened) } \\
\text { Neck granulations around catheter exit } \\
\text { site }\end{array}$ & & & $\begin{array}{l}\text { Re-bury unit if possible, other- } \\
\text { wise exteriorize in axilla }\end{array}$ & $\begin{array}{l}\text { Conservative measures. Care- } \\
\text { ful infrequent change of } \\
\text { dressings in view of risk of } \\
\text { dislodgement of catheter tip }\end{array}$ \\
\hline Heart failure despite satisfactory pacing & \multicolumn{4}{|c|}{ Rest. Digitalis and diuretics. Optimal rate of pacemaker needed } \\
\hline
\end{tabular}




\section{Pacemaker Units}

An external unit can readily be checked, and its batteries changed as required: they are set to deliver twice the optimum power needed at a voltage of at least $25 \%$ more than the threshold. The threshold for epicardial stimulation of the heart can be measured, and should be less than 4 volts at 2 milliseconds pulse duration, and the power required should not be greater than 40 microjoules. Figures above these levels indicate increased resistance in the circuit and suggest the presence of sepsis or tissue reaction.

The assessment of a buried unit is more difficult (Davies and Sowton, 1964). Using standard E.C.G. lead positions (lead I electrode position for unipolar axillary unit, and leads II or III for unipolar abdominal unit) to give the maximum deflection on a measuring oscilloscope, the height of the deflection is measured ; it should be greater than 120 millivolts for an epicardial unipolar system (but much less for a bipolar system, where 2-3 millivolts is acceptable), and 70 millivolts with a left axillary indifferent electrode, or 140 millivolts for a right-sided one, for an endocardial system of the type used at this hospital. Failure to pace may be absolute, such as from electrode breakdown, or relative, such as occurs when the threshold to stimulation rises to about the level of unit output, which is usually a manifestation of sepsis. Eventual battery exhaustion occurs in all units, and is often premature in implanted units, perhaps because of the higher environmental temperature.

\section{Sepsis and Rejection}

The sites of sepsis are around or over buried abdominal units and in thoracotomy scars. In both areas sinus formation is common, and a concomitant rise in threshold with intermittent or total failure of pacing is inevitable. Initially the patient presents with mild fever and tenderness over the implanted unit or in the thoracotomy scar at any time from one week postoperatively to as late as one year after implantation. Once a sinus appears, exteriorization of the unit and eventual change to a different system of pacing is inevitable. With buried axillary units, however, there is a striking absence of sepsis and rejection, but the lack of subcutaneous fatty tissue, particularly seen in thin men, has occasionally resulted in too superficial placing of the unit, with subsequent aseptic wound breakdown.

A low-grade granulation response at the site of exit of a jugular catheter is common, but significant local sepsis is unusual and rarely troublesome. Septicaemia has been seen, but only when the catheter is attached to an external unit, and repositioning of the catheter has been the precipitating factor. It is for this reason that long-term endocardial pacing with an external unit is contraindicated in patients with valvular disease, with their liability to bacterial endocarditis. Septicaemia had not been seen, however, when the endocardial system has been completely buried.

\section{Electrodes}

Detachment of epicardial electrodes may occur in the presence of gross sepsis, resulting in intermittent or failed pacing. Lesser degrees of separation of the electrodes from the epicardium may arise as a result of a sterile fibrous reaction at the site of electrode attachment, leading to a rise in the power required to pace the patient.

The tip of an endocardial electrode catheter may become dislodged from its position at the apex of the right ventricle, and lie free within the ventricular cavity, with consequent intermittent pacing. This is particularly liable to happen when the proximal end of the catheter is exteriorized at the neck, and changes of dressings covering the site of exit of the catheter are apt to disturb its position.
If dislodgement of a completely buried endocardial catheter tip is going to occur, it is usual for it to happen within one week of the original positioning and cause intermittent pacing. Late displacement has been seen only once, and in that patient an excess loop of catheter had been left in the right atrium 10 months previously, and could have pulled the catheter tip back out of the ventricle. Even after many months of satisfactory pacing, however, it is possible to dislodge the electrode catheter at the time of replacing a faulty unit in the axilla.

The site of an electrode tip and the need for repositioning can be assessed by $x$-ray screening with an image intensifier and the position compared with the antero-posterior and lateral films taken at the time of the original insertion.

On two occasions intermittent pacing has been caused by a crack in the electrode catheter; it was recognized on one occasion by resumption of regular pacing with pressure over the catheter in the neck, indicating that the site of the fracture was in the loop inserted to fix the catheter in the neck. The catheter is now sutured with less angulation, and a complete loop is avoided in totally implanted systems, where the risk of dislodgement is small.

Perforation of the heart by the tip of the catheter is rare, and is only liable to happen within 48 hours of positioning the electrode catheter ; it has not yet been seen as a late cause of interruption of pacing.

Indifferent electrodes may lose good contact with the tissues, and those made of stainless steel may fragment, resulting in intermittent pacing. A new indifferent electrode in the circuit restores pacing and confirms the cause of failure.

Stimulation of muscle adjacent to an indifferent electrode occasionally occurs, especially in thin patients, but is usually well tolerated. It does not result in a drain of unit power and often becomes less prominent in a fully mobilized individual.

\section{Connecting Wires}

Fractures along the course of epicardial wires have occurred, and are manifest by the absence of a pacemaker stimulus on the E.C.G., despite the fact that the implanted unit is discharging normally, as can be shown by holding over the unit a portable transistor radio turned to maximum volume but detuned between stations (optimum wave-length 400 metres), when a clicking from the loudspeaker indicates the pacemaker rate. Fractured wires may sometimes be located by means of an overpenetrated $x$-ray exposure. Since the development of an improved wire several years ago there have been no fractures of buried epicardial wires, but external wires and connexions are very prone to breaks, and as a precaution they are replaced every six months. The chances of breaks and faulty junctions are lessened by avoiding soldering, crimping, plugs, and sockets ; all junctions are made by multiple twisting, cutting strains down to a minimum.

\section{Routine Maintenance Programme}

Most patients attend at three-monthly intervals, but are asked to check their own pulse rate daily, and to contact the clinic at once if their rate varies or falls by 10 beats per minute. Recent modifications to the units and newer techniques have led us to anticipate fewer breakdowns and complications, and consequently less frequent attendances.

\section{Three-monthly Attendance}

1. Interview and clinical examination: with particular reference to: Syncope, palpitations, and exercise tolerance.

Check pulse over one minute.

Evidence of heart failure.

Inspect wounds/scars.

2. Long E.C.G. strip. 
3a. External pacemaker.

Check external wires and connexions and replace six-monthly.

Check power of pacemaker. Batteries changed 6- to 12monthly.

3b. Implanted pacemaker.

Check power with measuring oscilloscope.

\section{Results}

Ninety-six patients with permanent pacemakers have been followed up. The total number of faults and pacingbreakdowns has been large, but these are now becoming fewer with the introduction of better techniques. Furthermore, the majority of patients have been able to lead normal lives. Only one patient has died as a direct result of unit failure; the remainder survived a recurrence of Stokes-Adams attacks because of return of idioventricular rhythm giving sufficient time for restoration of artificial pacing.

\section{Summary}

Ninety-six patients with long-term artificial pacemakers have been followed up at a special out-patient clinic. Their types of pacing systems are described and normal pacing patterns are outlined. The causes of faulty pacing and their manifestations are discussed, with the techniques routinely used in the clinic to correct such faults and to maintain regular pacing.

REFERENCES

Davies, J. G., and Sowton, G. E. (1964). Phys. in Med. Biol., 9, 257. Harris, A., Bluestone, R., Busby, E., Davies, G., Leatham, A., Siddons, H., and Sowton, E.' (1965). "'The Management of Heart Block." Brit. Heart F., 1965 . In press.

Segel, N., Hudson, W. A., Harris, P., and Bishop, J. M. (1964). F. clin. Invest., 43, 1541.

Siddons, H., and Davies, J. G. (1963). Lancet, 2, 1204

Sowton, G. E. (1963). M.D. Thesis, Cambridge.

- and Davies, J. G. (1964). Brit. med. F., 1, 1470

\title{
Hodgkin's Disease, Autoimmunity, and the Thymus
}

\author{
B. I. HOFFBRAND,* M.A., B.M., B.CH., M.R.C.P.
}

Brit. med. F., 1965, 1, 1592-1594

The immunological features of Hodgkin's disease have been recently reviewed by Aisenberg (1964). The high incidence in this condition of certain infections, tuberculosis, cryptococcosis, and herpes zoster has been recognized for some years (Ewing, 1940 ; Collins et al., 1951 ; Williams et al., 1959). This susceptibility to predominantly intracellular organisms is now thought to be related to impaired tuberculin-like delayed hypersensitivity, an immunological defect found in a large percentage of patients with Hodgkin's disease, even at an early stage of the disease (Schier et al., 1956). The production of circulating antibodies, on the other hand, is generally well preserved (Aisenberg and Leskowitz, 1963) and frank hypogammaglobulinaemia is rare (Hoffbrand, 1964a).

There have been repeated suggestions that autoimmune mechanisms play a part in Hodgkin's disease. Kaplan and Smithers (1959) pointed out the similarities of graft-versus-host reactions such as runt-disease to Hodgkin's disease, especially to its occasional acute terminal illness with fever, wasting, anaemia, leucopenia, and lymphoid depletion. Green et al. (1960) suggested that Hodgkin's disease could represent a maternal-foetal lymphoid chimaera. Waksman (1962) includes Hodgkin's disease in a review of diseases of unknown aetiology in which autoimmunity may occur.

There are also numerous reports of the occurrence in Hodgkin's disease of disorders believed to have an autoimmune basis. Beuchart (1958) and Cammarata et al. (1963) describe cases of Hodgkin's disease, with clinical and pathological evidence of systemic lupus erythematosus (S.L.E.). Miescher and Vorlaender (1957) and Ogryzlo (1956) report cases with positive lupus erythematosus (L.E.) cell tests. Haematoxylin bodies, thought to be pathognomonic of S.L.E., have been found in Hodgkin's tissue (Candreviotis, 1962). Razis et al. (1959) found two cases of polyarteritis nodosa, one of probable scleroderma, and one with previous thrombocytopenic purpura treated by splenectomy among 1,102 cases of Hodgkin's disease. Hench et al. (1962) report 22 patients among 1,000 cases of unspecified lymphoma who had significant rheumatic complaints, including rheumatoid arthritis, S.L.E., and polyarteritis. Positive latex-fixation tests in the reticuloses, in the

- Medical Registrar University College Hospital, London. Present address: Whittington Hospital, London. absence of liver disease, have been attributed to abnormalities of the antibody-producing cells of the body (Innis and Ferguson, 1964). Howqua and Mackay (1963), in a paper describing the finding of L.E. cells, antinuclear antibodies (A.N.F.), and organ-specific antibodies in cases of malignant lymphoma, including Hodgkin's disease, discuss the significance of autoimmune phenomena in the reticuloses in terms of Burnet's clonal selection theory (Burnet, 1959).

Further possible pointers to the existence of immune mechanisms in Hodgkin's disease are the frequent occurrence in this condition of hypergammaglobulinaemia (Miller, 1962) and of involvement of the thymus (Thomson, 1955). The cause of the former is unknown. The significance, other than local, of the latter is also uncertain, though Thomson (1955) found a higher incidence of thymic involvement in females and an associated improved survival rate. Aisenberg (1964) has pointed out the need, with new knowledge of its function, for a reappraisal of the thymus gland in Hodgkin's disease.

This paper reports a study of thymic involvement and of clinical and serological evidence of autoimmune phenomena in Hodgkin's disease.

\section{Material and Methods}

The patients were 39 cases of histologically proved Hodgkin's disease attending the lymphoma clinic at University College Hospital. The histology of the gland sections had all been carefully reviewed and only those showing typical features of the disease were included (Hilton and Sutton, 1962). All the patients were seen regularly in the clinic, were fully documented, and had had chest radiographs carried out when first seen and at frequent intervals afterwards. All the patients, except for two not treated after the initial gland biopsy and one who had had drug therapy only, had had one or more courses of radiotherapy.

Radiological evidence of upper anterior mediastinal disease at any time during the period of observation was noted and assumed to indicate thymic involvement. Those without such changes were considered to have an uninvolved thymus. Such assumptions are obviously liable to error but were felt to be warranted for comparative purposes. 